\title{
Increasing Retention by Incorporating Time Management and Study Skills into A Freshmen Engineering Course
}

\author{
Walter L. Bradley and Steven Bradley \\ Baylor University/ 1QuestLearning
}

\section{Introduction}

The thesis of this paper is that the primary reason that students see their high school GPA drop by $\sim 1.0$ grade point their freshmen year in college is a lack of time management and study skills. ${ }^{1,2}$ As the table illustrates, learning in high school is primarily in class while a significant part of learning in college is outside of class, requiring up to $500 \%$ more outside study time than was required in high school. The slower pace and shorter assessment periods students have in high school allow them to develop the habit of procrastinating and cramming, with considerable academic success.

\begin{tabular}{|l|c|c|}
\hline & H.S. & College \\
\hline $\begin{array}{l}\text { Time spent in } \\
\text { class/wk }\end{array}$ & 30 & 15 \\
\hline $\begin{array}{l}\text { Study outside } \\
\text { class }\end{array}$ & 5 & $25-30$ \\
\hline Learning & Directed & Self-directed \\
\hline Environment & Dependent & Independent \\
\hline $\begin{array}{l}\text { Assessment } \\
\text { Periods }\end{array}$ & Short & Long \\
\hline
\end{tabular}

Table 1. High School vs. College Unfortunately, the much faster pace and longer intervals between assessments in college make the procrastinating and cramming strategy untenable.

This problem is particularly acute in engineering where the step-up from high school is much greater than in many majors, and procrastination in mastery of basic materials quickly leads to ineffective in-class learning. Helping entering freshman to develop effective time management and study skills will enable them to have the best possible chance of succeeding in their freshmen year and continuing in the engineering college. We believe that most students who drop out of engineering do so because they think it is too difficult, without recognizing that the real problem is their poor time management and study skills. The results to be presented in this paper will provide some empirical support for this hypothesis.

We wish to present the results of a study performed at Baylor University, where time management and study skills principles were integrated into a freshman-engineering course. We will describe the approach used to integrate these principles into the course and then present several quantitative measures of the efficacy of incorporating time management and study skills into freshmen engineering classes, including retention and GPA for freshmen engineering students. Results will compare classes from Fall 2002 to Fall 2003, where the same teaching team taught the course to $\sim 75$ students with nominally the same qualifications, one class without 
time management and study skills instructions and the other with such instruction incorporated into the course.

\section{Incorporating Time Management and Study Skills into Freshman Engineering}

One of the challenges to incorporating time management and study skills into a freshmen engineering course is the need for it to take minimal time, but nevertheless, be effective in reshaping the habits of the freshmen students. At Baylor University, we adopted an inexpensive program ( $\sim 10$ /student) called Success 4 Students that has been designed for engineering students. The program is a video/workbook seminar that can be presented in three hours, with the professor serving as the facilitator for the program. The fifty-page workbook includes 25 pages of notes that follow the video presentation and 25 pages of application activities that the students complete at the end of the various video segments at the workshop.

The seminar has six segments that address the following topics:

- Select your destination (where do you want to be in five years);

- Determine your path (focusing on goal setting for the semester);

- Planning to succeed (emphasizing the importance of planning your schedule for the week each Sunday and then following it like a compass through the week);

- Maximizing your in-class learning by

- Staying caught up in your understanding

- Reviewing your notes between classes to be sure your are current

- Reading the material to be covered in class before it is covered

- Learning material each week as if the exam were on Friday of that week

- Overcoming academic procrastination

$\circ$ Working especially hard the first three weeks of the semester

- Listening more carefully and taking notes more selectively

- Getting 8 hours of sleep/night and exercising regularly

○ Treating school like an 8-5 job, working at least 40 hours/week

- Speed Reading and Learning to triple your reading speed with better comprehension by

○ Previewing

○ Pacing

- Creative note taking and memory skills

The video format is an interesting discussion between five students and a professor in a coffee shop setting. The program is effective as students are often very receptive to advice from older peers, especially when students are talking about the academic pitfalls they have encountered. Each 20-minute video segment is followed by a 10-15 minute application activity done in the student workbook.

Possibly the most innovative feature of the Success 4Students seminar is the 12 weeks of Internet follow-up that includes a weekly assessment. Students receive an e-mail automatically each Friday reminding them to follow the link to the Success4Students website where they can score themselves on their application of the key principles taught in the seminar. After completing the assessment, which takes 2-3 minutes, they get a numerical score on a scale of $0-100$, their scores 
from previous weeks, and an indication of the average score for all students who have done the assessment for that week. This allows them to measure their academic effort (above or below average) and to see their improvement (hopefully) as they develop the principles taught in the seminar into habits. More details about the Success4Students (Video) Seminar and Internet follow-ups can be found at www.success4students.com.

For my freshmen engineering courses at Baylor University, I had all the students come to an evening presentation of the seminar the first week of the semester, and their attendance counted as their homework for that week. I used a survey that students took at the conclusion of the seminar to measure student response to the seminar. The results were overwhelmingly positive, with 39 indicating the were very satisfied with the seminar, 33 indicating that they were satisfied, and only 1 indicating disappointment with the seminar. Of the 72 students who took the seminar, 71 indicated that they would recommend this seminar to friends, and indeed they did. I had students inquiring all semester about how they could take the same seminar.

I gave students 3 points of bonus credit to their semester average for completing all of the 12 weeks of assessment ( 0.25 points/assessment completed). I was able to view their weekly assessment scores at the Success4Students website where the students' scores for all weeks are recorded in a table. This allowed me early in the semester to conveniently identify students who were not applying themselves effectively and provide some additional encouragement. The students who made low GPAs were generally the same ones who either did not complete the assessment or had a low assessment score. The effort in presenting the seminar using the facilitator's manual was minimal and the 12 weeks of Internet follow-up is completely automated. Occasionally checking the table at the website to see how the students were doing on their weekly scores allowed us to identify students who were off to a slow start so that we could provide them extra encouragement and help.

At other universities, the video seminar has been presented in several class periods early in the semester to help the students get a picture of what it will take to succeed in college before they get too far behind.

\section{Time Management and Study Skills in Freshmen Engineering: Measures of Impact}

Two measures of the efficacy of the program were used: persistence (or retention) of students in engineering the following semester and GPA for the semester. A longer-term study is in place to see if the improved persistence is temporary or permanent. The results are presented in Table 2 .

\begin{tabular}{|lcc|}
\hline & GPA & \% Retention \\
\hline F2003 (w/ study skills) & 3.13 & 83 \\
F2002 (control group) & 2.59 & 67 \\
\hline
\end{tabular}

Table 2: GPA and retention improvement with time management and study skills program

\section{Correlating Academic Performance with Overall Assessment Scores and Individual Items}

The weekly assessments provided very detailed data regarding what students did each week throughout the semester to apply themselves academically. A statistical analysis may be used to 
determine the relative importance of the various items measured in the assessment on their resultant GPA. The scatter in such an exercise will be large because the students vary widely in their natural ability and preparation as incoming freshmen, and there is no way to control for these hidden variables. We are examining only the contribution of their time management and study habits to their success, while ignoring their natural ability and academic preparation.

A portion of the weekly evaluation is seen in Figure 1. For each item the students get from 1 and 5 points, depending on the effort they indicate on that item. Some items have been assumed to be more important, and these items have been assigned a double weighting, as seen in Table 3 . The items given a double weighting include (1) preparing a weekly schedule, (2) following the weekly schedule, (3) reading the textbook before material is covered in class, (4) staying current in understanding in all classes, and (5) total time spent in class and studying.

Students will get a score of between 0 and 100 each week when they complete their weekly assessment. This score is a measure of their academic effort. They will also get the average score for all students who have completed the assessment for that same week, allowing them to get an indication of their academic effort compared to other students. In addition they will also receive their weekly scores for all previous weeks so that they can see if they are improving their academic effort week by week by developing better time management and study habits.

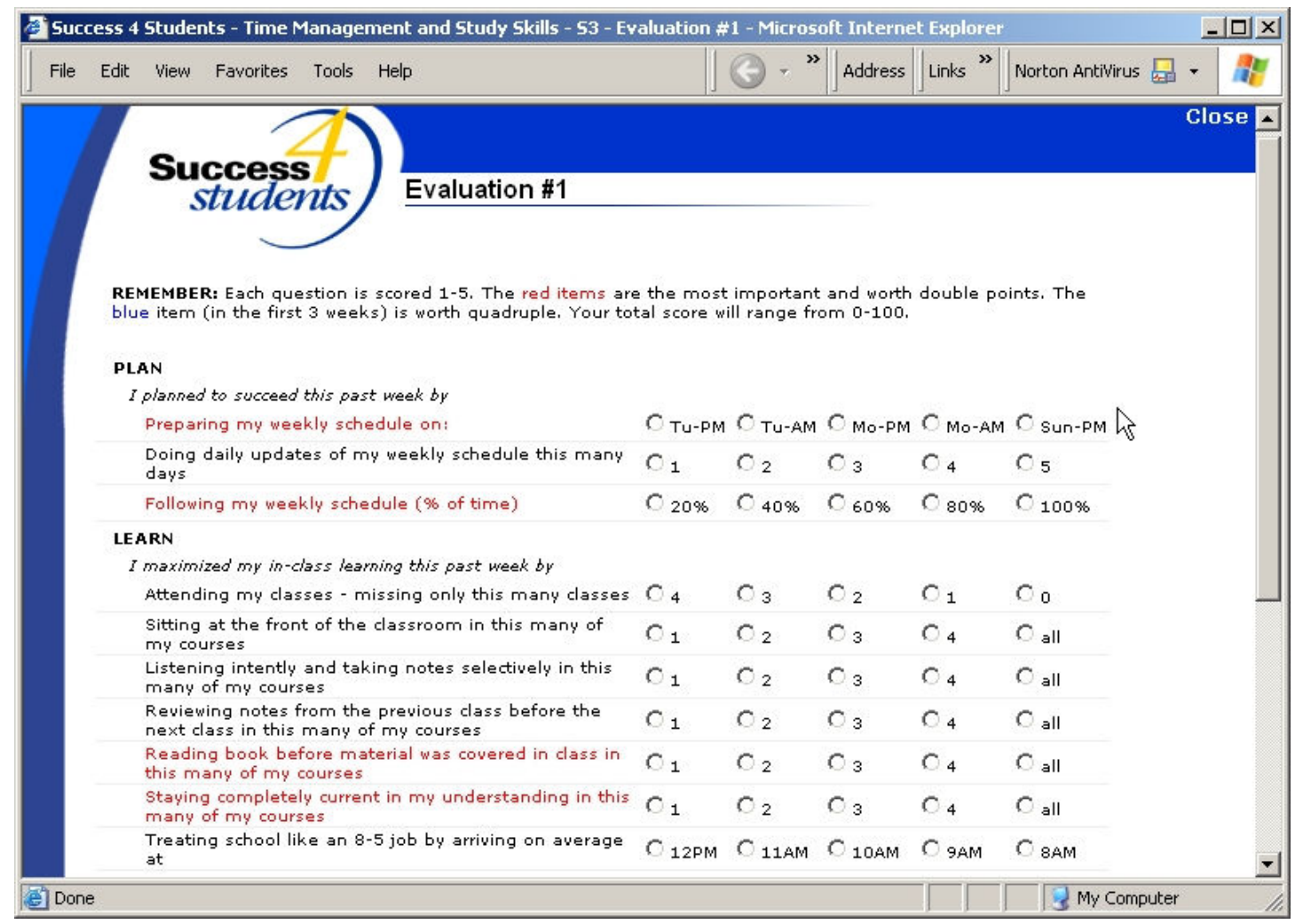

Figure 1: Weekly evaluation example

The semester GPA for each student versus the student's average weekly assessment score for the semester is presented in Figure 2, where the average weekly assessment scores were first divided by 100 to give a rank of 0 to 1.0 (rather than $0-100$ ). The results give the expected positive 
correlation between GPA and academic effort, as measured by the average weekly assessment score, and nor surprisingly, a consider amount of scatter.

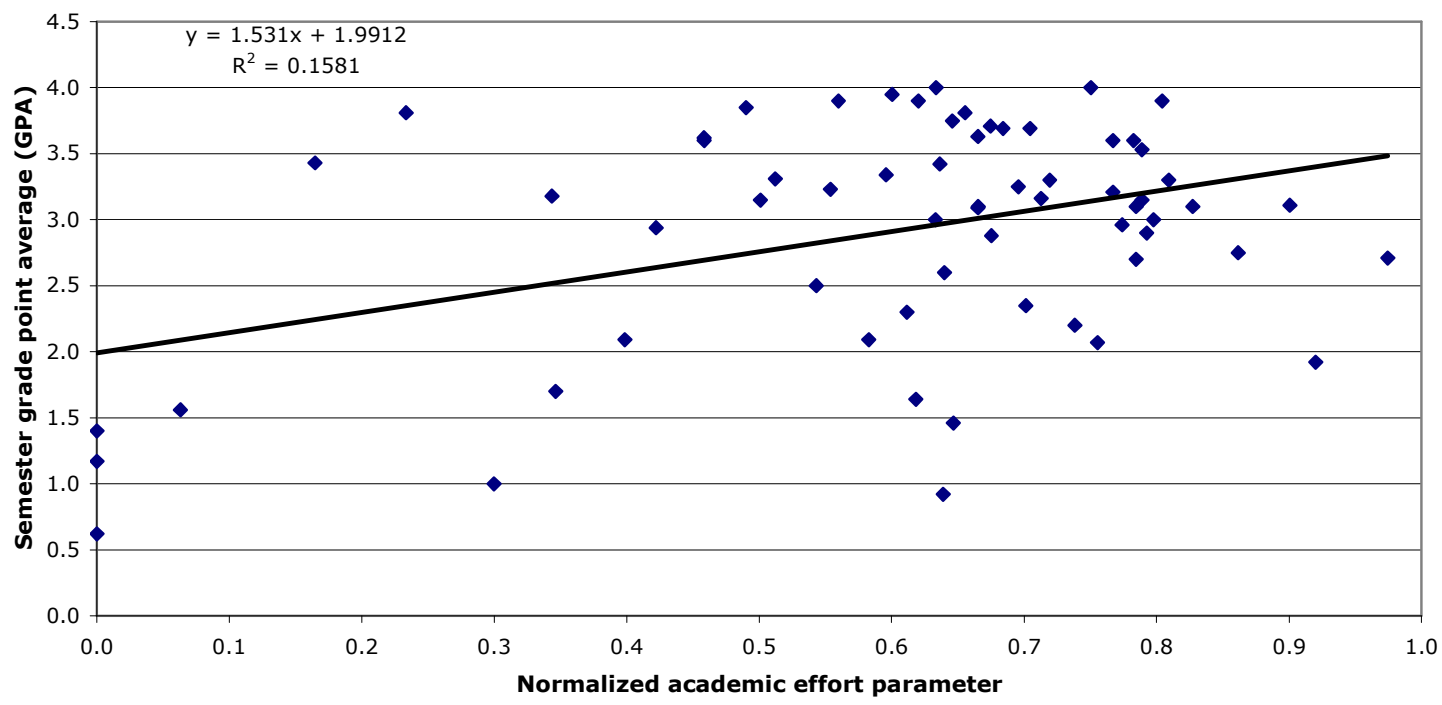

Figure 2: GPA vs. Average Weekly Assessment Score for Semester (Original weighting)

As previously noted, in the initial calculation of the weekly assessment scores, some items were thought to be more important than others, and therefore, were assigned a higher weighting, as seen in Table 3. However, the weekly assessment data provided sufficient information to allow these weighting factors to be determined empirically. The semester average for each item in the evaluation was determined for each student. Then the students' semester GPAs were plotted against their respective semester averages for each item in the weekly assessment. A linear regression was used to determine the slopes of GPA versus Class Attendance, GPA versus "Treated School Like 8-5 Job", etc. with the results summarized in Table 3. The slope of 1.81 for GPA versus Class Attendance means that a student who missed no classes per week made a 1.81 higher GPA than a student who missed 4 or more classes per week. The student who started their school day at 8:00 A.M. had a 1.77 higher GPA than the student who on average started their school day at 12:00 noon.

Dividing each slope in Table 3 by 1.81 allowed the relative importance of various items to be more easily seen in the column labeled "Ratio". The sum of all items in the column labeled "Ratio" divided into each item in the column gives the respective weighting factors for the various items. Each weighting factor is a measure of the relative importance of the students' effort in that area for the GPA they earned. The new, and hopefully improved, weighting factors were used to recalculate the average weekly assessment score, which measures their overall academic effort. The students' GPAs versus their respective average weekly assessment scores calculated using the new weighting factors is presented in Figure 3, and is seen to have an increased slope (or sensitivity) and a much better correlation coefficient compared to Figure 2, where the average weekly assessment scores were calculated using the original weighting factors. 


\begin{tabular}{|l|c|c|c|c|}
\cline { 2 - 5 } \multicolumn{1}{c|}{} & \multicolumn{1}{c}{ Slope } & \multicolumn{1}{c|}{ Ratio } & Weighting Factor & Original Factor* \\
\hline Class attendance & 1.81 & 1.000 & $10.39 \%$ & $5 \%$ \\
\hline Treated School like 8-5 Job & 1.77 & 0.98 & $10.15 \%$ & $5 \%$ \\
\hline Hours Spent on Coursework/Week & 1.71 & 0.95 & $9.85 \%$ & $10 \%$ \\
\hline Stayed Current in Understanding & 1.50 & 0.829 & $8.61 \%$ & $10 \%$ \\
\hline Listened and Took Notes & 1.45 & 0.799 & $8.31 \%$ & $5 \%$ \\
\hline Average Sleep/Night & 1.34 & 0.74 & $7.68 \%$ & $5 \%$ \\
\hline Followed Schedule (\%) & 1.22 & 0.672 & $6.99 \%$ & $10 \%$ \\
\hline Updated Schedule & 1.02 & 0.561 & $5.83 \%$ & $5 \%$ \\
\hline Read Book Before Class & 1.01 & 0.559 & $5.81 \%$ & $10 \%$ \\
\hline Previewed/Paced in Reading & 0.97 & 0.54 & $5.56 \%$ & $5 \%$ \\
\hline Sat in Front & 0.93 & 0.512 & $5.32 \%$ & $5 \%$ \\
\hline Reviewed Notes & 0.89 & 0.490 & $5.09 \%$ & $5 \%$ \\
\hline Prepared Schedule & 0.76 & 0.421 & $4.37 \%$ & $10 \%$ \\
\hline Radiant Notes & 0.59 & 0.33 & $3.38 \%$ & $5 \%$ \\
\hline Used Memory Techniques & 0.46 & 0.26 & $2.66 \%$ & $5 \%$ \\
\hline
\end{tabular}

Table 3: Slopes and weighting factors

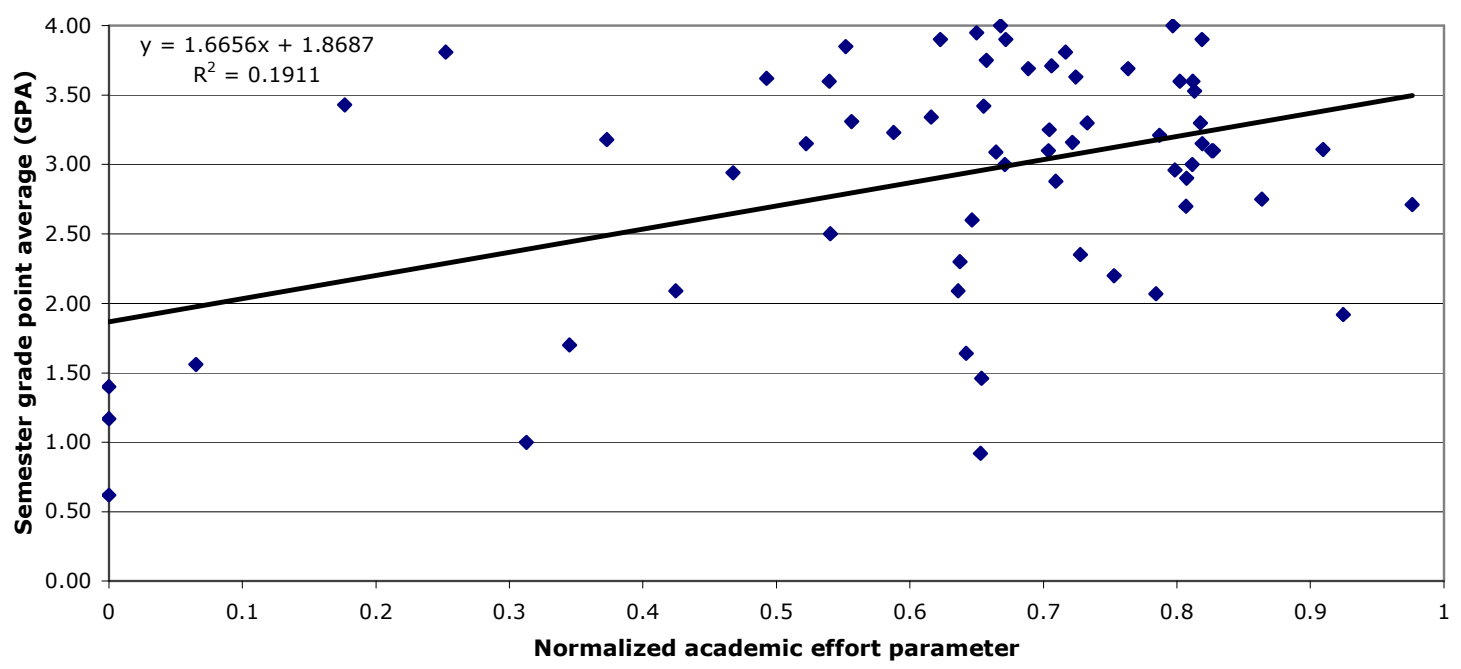

Figure 3: GPA vs. Average Weekly Assessment Score (New Weighting)

To eliminate additional scatter due to effects other than student effort, we will need to adjust the weekly assessment scores to take into account high school preparation and natural ability. Some students who made a high GPA despite having a relatively low score on their weekly assessment would be shifted horizontally to the right because they came in well prepared and/or were extremely bright. Other students who had a high weekly assessment score but a relatively low GPA would be shifted horizontally to the left due to poor academic preparation or below average (compared to peers) ability, improving the overall correlation coefficient for the linear regression. What Principles should be emphasized to increase academic performance? 
The items with the highest weighting factors in Table 3 are the principles that should be emphasized to freshmen engineering students to help them succeed. It is likely that this weighting changes as students matriculate through college. For example, a freshmen from a good high school may find considerable subject material that is a review from high school, making reading the book before material is covered in class less important. As they encounter material that is both more complex and less familiar, reading the book before the material is covered in class will become increasingly important.

\section{Additional Antidotal Information on Freshmen Academic Performance}

One of the common problems some students have is getting to bed on time. This is easily evidenced in my 9:00 A.M. class by chronic late arrival and absenteeism or poor attention in class. The reasons or excuses given by students for this problem varied from roommates who stay up late playing on their computers to an excessive dependence in high school on parents to regulate their going to bed and getting up at the proper time. Most students sleep much less than 8 hours per night, and thus, have real difficulty paying attention in class or studying efficiently. A second common problem is a failure to apply themselves with intensity the first three weeks of class. Freshmen are both dazzled with the many interesting diversions college life brings as well as naïve about the risks of falling behind in their learning. In high school, the pace is slow enough and the interval between exams short enough that cramming often works, unfortunately. This is often not the case in college, and once a student falls behind, their in-class learning is minimal and they are now left with the formidable job of teaching themselves, which is not likely in mathematics, science, or engineering classes.

I had several students who came by during the Fall 2003 who had taken my freshmen engineering class, including Success4Students with the assessment, in the spring of 2003. These students who had made 3.5 GPAs or better were now struggling because they had failed to continue to practice what they learned that first semester. I put each of them back on the weekly assessment and they were able to recover significantly by the end of the semester.

\section{Summary}

Introducing basic time management and study skills into freshmen engineering classes can help students to quickly adjust academically to college and avoid changing majors by changing their time management and study habits. After incorporating time management and study skills into our freshmen engineering classes, the retention rate increased from $67 \%$ to $83 \%$ and the freshmen GPA increased from 2.59 to 3.13. One simple approach to teaching time management and study skills to freshmen and helping them develop new habits is to use a video seminar like Success 4Students with Internet follow-up.

\section{References}

1. UC and the SAT: Predictive Validity and Differential Impact of the SAT I and SAT II at the University of California, Oct. 2001.

2. Georgia Institute of Technology, Faculty Senate Minutes, Item 5, February 2002.

\section{Biographical Information}


WALTER L. BRADLEY

Walter Bradley received his B.S. in Engineering Science and his Ph.D. in Materials Science and Engineering from the University of Texas (Austin). After 8 years at Colorado School of Mines and 24 years at Texas A\&M University, Dr. Bradley is a Distinguished Professor of Engineering at Baylor University. His research interests include mechanical properties of materials.

\section{STEVEN W. BRADLEY}

Steven Bradley received his B.S. in Chemical Engineering from the University of Texas (Austin) and his M.E. in Mechanical Engineering from the Texas A\&M University. He is the founder and Chief Operating Officer of 1Questlearning, a company that creates resources that help high school and college students to develop better time management and study skills. He produced the video workshop Success4Students that was used in this study. See www.Success4Students.com for more details about 1Questlearning and the Success4Students video workshop. 